\title{
Repensando un modelo inclusivo de educación desde el pensamiento complejo para la enseñanza de los derechos humanos
}

Rethinking an inclusive model of education from complex thinking for the teaching of human rights

\author{
Laureano, Redondo-Duran ${ }^{1}$
}

Universidad Simón Bolívar

DOI: http://dx.doi.org/10.29105/pgc4.8-2

https://orcid.org/0000-0002-1923-7433

\section{RESUMEN}

El presente artículo es producto de una revisión bibliográfica, cuyo objetivo consistió en analizar la educación en relación con los derechos humanos en Latinoamérica. Se aplicó el método de análisis, con un enfoque cualitativo, diseño no experimental, bajo un nivel documental-bibliográfico transversal. Tras la revisión documental se encontró que: realizar un análisis del sistema educativo en la región latinoamericana es muy compleja y es necesario mirar hacia otras vías para poder realizar este análisis. Se concluye que existe una falencia en materia de educación de derechos humanos lo que no permite tener una verdadera cultura de paz.

Palabras clave: Creatividad, crisis, comportamiento, derechos humanos, dialogo y multiculturalidad.

\section{ABSTRACT}

This article is the product of a bibliographic review, which objective was to analyze education in relation to human rights in Latin America. The method of analysis was applied, with a qualitative approach, non-experimental design, under a transversal documentary-bibliographic level. After the documentary review it was found that: carrying out an analysis of the education system in the Latin American region is very complex and it is necessary to look towards other ways to conduct this analysis. It is concluded that there is a lack of human rights education which does not allow for a true culture of peace.

Key words: Creativity, crisis, behavior, human rights, dialogue and multiculturalism

Cómo referenciar este artículo:

Redondo-Duran, L. (2018). Repensando un modelo inclusivo de educación desde el pensamiento complejo para la enseñanza de los derechos humanos. Revista Políticas, Globalidad y Ciudadanía, 4(8), 20-36. Recuperado de http://revpoliticas.uanl.mx/index.php/RPGyC/article/view/100

Recibido: 11 de Enero 2018 - Aceptado: 02 de Marzo 2018

(cc) EY-NC-ND

\footnotetext{
1 Magíster en Educación. Profesor Investigador, Universidad Simón Bolívar. Email: 1redondo@unisimonbolivar.edu.co

Revista Política, Globalidad y Ciudadanía, Vol. 4 No. 8, Julio - Diciembre 2018, Universidad Autónoma de Nuevo León, Monterrey, México, ISSN 2395-8448. pp 20-36. http://revpoliticas.uanl.mx/index.php/RPGyC/article/view/100
} 


\section{INTRODUCCIÓN}

Los derechos humanos les pertenecen a todas las personas desde el primer momento de su vida, independientemente de sus escenarios y calidades únicas. Por eso la educación de los derechos humanos en todo momento histórico ha sido de suma importancia para la educación del futuro y sin olvidar la importancia de estos en el pasado. Los derechos humanos son un tema bastante discutido. En esta cultura dominante, que hemos catalogado como "postmoderna" y que de la modernidad solo ha mantenido la tecnología, es una cultura cada vez más al lado de los derechos humanos. Según el programa mundial para la educación en derechos humanos (en curso desde 2005): Los derechos humanos deben ser entendidos dentro del movimiento magno de pensadores, filósofos y ciudadanos del mundo. Ellos han pensado en reivindicar en la historia los derechos de todos los ciudadanos, resaltar su dignidad y mirar su alteridad en un contexto que siempre ha sido el contexto de la violencia y la guerra que es también obligación de todos los formadores planetarios.

En esta dirección se puede considerar de particular interés, de la misma manera, asociar las ideas que guardan relación con el tema de la interculturalidad y los procesos de aprendizaje, tales como lo enseña el pedagogo Paulo Freire: "El dialogo es una exigencia existencial. Y siendo el encuentro que solidariza la reflexión y acción de sus sujetos encauzados hacia el mundo que debe ser transformado y humanizado, no puede reducirse a un mero acto de depositar ideas en un sujeto en el otro, ni convertirse tampoco en un simple cambio de ideas consumadas por sus permutantes" (Freire, 1998: 101).

Existen otras formulaciones de orden históricas que también hacen referencia al tema desde una perspectiva similar con respecto a los derechos humanos y la multiculturalidad. Estos hacen énfasis sobre el reconocimiento a la paz y a las diversidades. Afirman: que no puede obviarse bajo ninguna circunstancia los procesos de guerras internas vividas en países de América Latina entre los años 1970 y el 2000 en la región Centro americana y en países de américa del sur respectivamente. Siendo que los procesos de amnistía y de paz consecutivamente permitieron la apertura a espacios de negociación en el seno de las sociedades nacionales. Fue precisamente el país guatemalteco quien sirvió como paradigma para entender lo cruel de una guerra que arrasó de manera inmisericorde con una gran parte de una cultura histórica como fue la Maya. Pero no hay mal que por bien no venga; este conflicto permitió una paz y un tránsito democrático y solidario, haciendo posible el reconocimiento de las diversidades étnicas (Moya, 2009).

América latina al igual que otros espacios del universo ha sido y sigue siendo el escenario de la violencia de todo tipo. Sin embargo, podemos afirmar que en todas las sociedades del mundo existe la violencia y se piensa en la paz. En todo caso es admisible la idea expuesta por Morín, al reflexionar en torno a la cultura y a la violencia. Por eso plantea la imperiosa necesidad de "desocultar, de revelar, en y por su diversidad, la unidad de la especie, la identidad humana, los universales antropológicos. La identidad del hombre, es decir, su unidad/diversidad compleja se vio ocultada y traicionada, en el corazón mismo de la era planetaria por el desarrollo especializado/compartimentado de las ciencias" (Morín, 2006: 64).

Esta situación nos conduce directamente a mirar de una manera diferente, y por decirlo así sería una forma de hacer compleja la situación y llevarla al aula a través de una flexibilidad transhumanista, con el dialogo con los otros por medio de un método transdisciplinar ya que la educación no está a la altura de los tiempos y después de la unidad, viene la complejidad y haciendo posible un verdadero pensamiento crítico, que no separe, que no sea visto estudiado el problema desde el ojo de una sola disciplina sino que una y permita estudiar todos los problemas de manera transdsiciplinar en un tejido, denominado: pensamiento complejo.

Asistimos hoy a un debate bastante neurálgico. Estamos ante un problema bastante gigante que nos insta a cambiar y hacer del proceso de aprendizaje un sistema que permita a las nuevas generaciones formarse de manera integral, que permita un giro cualitativo hacia la educación. Es preciso cambiar profundamente

Revista Política, Globalidad y Ciudadanía, Vol. 4 No. 8, Julio - Diciembre 2018, Universidad Autónoma de Nuevo León, Monterrey, México, ISSN 2395-8448. pp 20-36. http://revpoliticas.uanl.mx/index.php/RPGyC/article/view/100 
el pensamiento y la enseñanza. Su forma profunda contribuirá principalmente a realzar sobre los peligros enormes y la comunidad de destino, al mismo tiempo, hará posible y visible la acción transformadora desde la base. Hay que hacerles frente a los desafíos que nos presenta la posmodernidad y los planteamientos venidos desde la tercera ola de la que nos habla de manera contundente el teórico (Toffler, 1987).

Es preciso a la vez, globalizar y desglobalizar, crecer y decrecer, desarrollar, e involucionar, conservar y transformar. Es una obligación en este sentido del que se refiere, deshacernos de las alternativas globalización/desglobalización,crecimiento/decrecimiento,desarrollo/involución,conservación/ transformación como premisas necesarias que no serán nada fácil de transitar y de lograr, dichas alternativas como tal expresan un pensamiento dicotómico, segmentados y al mismo tiempo simplificador, propio de la clásica ciencia positivista, que es reductora y compartimentado en el contexto de la ciencias en este caso de la educación, que es el tema que estamos estudiando. (Morin \& Delgado, 2016).

La creatividad, hoy en el aula es muy importante para destacar y despertar el sentido del amor de los seres humanos y la construcción de un modelo de formación personalizante. La educación debe ser trasparente y debe estar orientada hacia al mantenimiento de las estructuras sociales y económicas. Entonces habrá una sociedad nueva, cuando tengamos hombres nuevos, los cuales sean gestores y creadores. Estos hombres se forjan en contacto "el que es la verdad", el único que entrega la auténtica libertad humana, y si de humanismo se trata es importante asumir junto con la educación católica, ya que esta es liberadora por ser evangelizadora. Para la iglesia en este caso la católica, educar al hombre es parte integral de su verdadera misión predicadora y evangelizadora. Esta educación según el documento de la misma iglesia tiene como finalidad anunciar de forma explícita al cristo liberador.

Se tiene en cuenta también en esta polémica, las contribuciones que hace Dewey en torno a la forma de como capacitar a los jóvenes, para compartir una vida en común, y cuál será la forma más eficaz para alcanzar este objetivo en una sociedad compleja como este afirma: "que no es posible que niños y jóvenes aprendan directamente por medio de la participación en las actividades realizadas por las personas adultas. Por esta causa aparecen las denominadas Instituciones Intencionadas, con el objeto de preparar a la juventud de manera tal que este pueda llegar a ser un miembro adulto con la capacidad y disposición de participar y desenvolverse de manera permanente en su propia comunidad" (Dewey, 1917: 18).

\section{2.- FUNDAMENTO TEÓRICO}

\section{La Complejidad del proceso creativo}

Los cambios sociales y culturales que ha provocado la globalización, el impacto cultural, radicalizado por el modelo neoliberal, que se ha convertido en una potente ideología hasta los momentos actuales más conocida, sigue adquiriendo un carácter de sacralidad, hasta transformarse en una especie de religión nueva, con los elementos también reforzados como una nueva idolatría, imponiendo un mercado único, representado este por la ideología neoliberal, que excluye y condena a la miseria a los más pobres (Peresson Tonelli, s.f.).

Haciendo referencia al problema del mercado neoliberal, es oportuno vincular el todo con las partes, de pronto son aquellos que ese modelo mercantilista y utilitarista no tiene en cuenta; tal como lo presenta (Goicovic, 2015): son los cambios sociales y culturales que la globalización a la que estamos referencia han provocado en la humanidad y que son estos los que han abierto la necesidad de desarrollar importantes trasformaciones en los procesos de aprendizajes en las nuevas generaciones, siendo que existen ya las posibilidades de mirar otras alternativas que enfrenten estas formas de exclusión en todos los ámbitos, en especial la educación en los niveles de la educación superior con nuevas urgencias de educación. 
Existe una relación muy estrecha entre la creatividad y la educación. El tema es expuesto desde muchos ámbitos de lo educativo, por ejemplo, asumimos la posición que al respecto nos brindan algunos teóricos: La creatividad radica especialmente en la capacidad y la actitud para dejar huellas de tipo personal, social e institucional. Esto permite generar un:

- Potencial personal o grupal, producto de la interacción de un conglomerado de dispositivos socioculturales, psicoactivos y biológicos donde la potencia mental vinculada a lo emocional resulta clave.

- Una orientación especialmente hacia una actitud abierta y flexible, con disponibilidad para sacar provecho de los estímulos brindados por el medio.

- Comunicación y expresión de ideas, comportamientos y realizaciones que tienen como resultado la originalidad, de interés personal, como un bien social y de la colectividad en común

- de proyección hacia los demás, de orden personal con la capacidad de impactar y con la posibilidad de transformar el entorno de los seres humanos en pro de una mejor vida (Saturnino \& Violant, 2003)

Un modelo educativo basado en la inclusión y convivencia

Hablar para una educación para la inclusión, la convivencia y los derechos humanos para el territorio de la América Latina, nos obliga a revisar y resignificar el concepto educación, máxime si se trata de formar en los valores de convivencia pacífica, el fenómeno de la inclusión o en su defecto los derechos humanos. Desde hace muchos años se vienen pregonando diversos discursos sobre el proceso de aprendizaje y sus diferentes problemas en nuestro territorio colombiano. No se puede decir que estos modelos propuestos desde afuera hayan sido todos exitosos o en su defecto desastrosos. Lo que si hay que tener en cuenta es que estos en los momentos actuales ya no dan respuestas positivas a las generaciones actuales, ni tienen la posibilidad de hacer posible el cambio que requiere nuestra sociedad.

Se supone que hablar de una educación con los viejos sistemas o paradigmas, para ser un poco más explícito ya no tiene ninguna respuesta. A propósito de este punto, nos dice (Morín \& Delgado, 2016: 35): “El saber científico sobre el mundo, situado por encima de las comunidades y las personas, se enfrenta hoy a nuevos problemas para los que no tiene respuesta, por que escapan a su racionalidad instrumental subyacente" Esto nos convoca a mirar el papel que ha mantenido Las ciencias, desde la modernidad; estas ciencias nos hicieron creer que todos los fenómenos se podían conocer, mirar conducir, incluso de manera exacta y sin equívocos en favor de la humanidad, hoy en pleno siglo XXI estas ciencias enfrentan a un conjunto a conjunto de fenómenos de todo tipo, que no pueden ser estudiados desde una sola mirada, y estos requieren de múltiples disciplinas para poder ser comprendidas como problemas.

Dentro de este cumulo de problemas el proceso de aprendizaje es esencial para entender y transformar el mundo de hoy, tomar conciencia del papel de esas redes electrónicas donde la información acumulada podría tomar las riendas de esa creatividad y por ende de la conducta humana de este siglo, sabias las apreciaciones destacadas desde la óptica de los retos de la educación en la modernidad liquida: "Después de todo, el aprendizaje y la educación fueron creados a la medida de un mundo que era duradero, esperaba continuar siéndolo y apuntaba hacerse aún más duradero de lo que había sido hasta ese entonces. En ese mundo duradero, la memoria era considerada como un valor positivo. Asistimos hoy a un mundo volátil de cambios instantáneos y erráticos, costumbres solidas establecidas y arraigadas por la tradición, marcos cognitivos y procesos de aprendizajes sólidos también, la plena validez de los valores sólidos y estables, esos objetivos hoy quizás se tornan desventajosos y producen una quiebra entre el ayer y el hoy en el denominado mercado del conocimiento. Por ese motivo, la llegada de la sociedad moderna liquida significó la desaparición de las utopías centradas en la sociedad y en general de la misma sociedad denominada "buena" (Bauman, 2005)

Revista Política, Globalidad y Ciudadanía, Vol. 4 No. 8, Julio - Diciembre 2018, Universidad Autónoma de Nuevo León, Monterrey, México, ISSN 2395-8448. pp 20-36. http://revpoliticas.uanl.mx/index.php/RPGyC/article/view/100 
Para ser efectivo y hacerles frente a los retos dilucidados desde la modernidad liquida al problema de los problemas y poder transformar el pensamiento, es necesaria la reinvención de la educación que integre y permita comprender que las poli crisis ocultan y develen a cada vez una crisis mayor, que es la crisis de la humanidad que puja por alcanzar a ser humanidad, ya que el contexto en que se desenvuelve la vida y la educación en los momentos actuales, es el de la poli crisis de la humanidad: una poli crisis que a su vez solicita la creatividad y audacia para enfrentar los abismos que se nos vienen encima cada vez más. Necesitamos con urgencia reinventar una educación superior para que se formen hombres capaces de combatir con los desafíos globales y planetarios de esas polis crisis (Morin \& Delgado, 2016).

Es de esta manera como lograremos una sociedad que ponga en práctica los valores de la solidaridad y el respeto por las diferencias de los demás; donde todos quepamos.

Fines de este modelo educativo

La finalidad de la educación en todo momento siempre ha sido la de contribuir enormemente a la integración y cohesión social. Pero a pesar de este propósito en algunas sociedades se viene desarrollando una práctica de exclusión y marginamiento a grandes masas. A esto se le puede sumar, otros fenómenos que demuestran la falta de cobertura en educación, salud, recreación y aspectos tales como la falta de oportunidades a las personas con discapacidad de todo tipo, generando una enorme desigualdad, siendo el resultado una exclusión a todos los grupos étnicos y comunidades afrodescendientes habitantes del territorio nacional.

En este sentido el propósito consiste primordialmente en mirar y desarrollar un modelo inclusivo de educación para los derechos humanos para el contexto de América Latina que sea acorde a las urgentes necesidades de su entorno sociocultural y la puesta en marcha de políticas educativas que permitan la convivencia sana de las comunidades a pesar de las grandes diferencias que por año los distancian; siendo que la educación intercultural es clave para desarrollar una eficiente educación en los derechos humanos asumida de una manera crítica dirigida hacia una buena comprensión hacia la diversidad étnico-cultural, una dirección que permita de igual forma hacer realidad o materializar los vínculos positivos entre los distintos grupos culturales, hacerle frente a la xenofobia, la discriminación y la exclusión. (Walsh, 2009: 9-11).

Heterogeneidad de la sociedad latinoamericana y los derechos humanos

América se encuentra catalogada como una sociedad multicultural en la que se puede encontrar diversas culturas. Esta sociedad abarca lo diverso del conjunto de costumbres de todas estas comunidades. Lo multicultural guarda una relación muy cercana con la problemática que vive el mundo por la discriminación planetaria. Existe Una variada gama de conceptos que involucran de forma sistemática el análisis y conceptualización de la diversidad en todos sus ámbitos. Existe un sistema intelectual que involucra la multiculturalidad, y es precisamente la producción norteamericana.

Desde esa perspectiva intelectual denominada norteamericana, solo se hizo uso del término multicultural desde una visión, que hacía uso de la "tolerancia" y el respeto por la "diversidad" desde lo meramente social. Estos lineamientos emergen al coger el hatillo o sea en otras palabras, que cada grupo se ubique en su lugar sin perturbar al otro. Al mismo tiempo y desde esa misma perspectiva se desarrollan y se hacen practicas las decisiones de políticas públicas, cuyo objetivo está dirigido exclusivamente a garantizar la igualdad en el acceso a los múltiples servicios que debe ofrecer el Estado o los gobiernos de turno a las personas (CENEP, 2008).

Contando con el apoyo de pensadores, antropólogos, geógrafos y sociólogos, es pertinente tomar en cuenta sus diferentes percepciones y afirmaciones sobre el fenómeno del multiculturalismo en el actual milenio, y de igual forma los vínculos existentes entre educación y derechos humanos para la mejor convi- 
vencia, la formación integral y el uso apropiado del Estado social de derecho y la igualdad de oportunidades en el caso de Colombia. Por ejemplo: la diferencia cultural se cree, afectan la igualdad de oportunidades. El multiculturalismo cree que deberíamos extender los derechos humanos a los derechos culturales. La cultura, en un vasto sentido en donde se incluye la lengua, la pertinencia nacional y las creencias religiosas, es un tejido necesario para que el conjunto de individuos pueda optar su propio modo de vida y su manera de trabajar (Puyol, 2008: 67-81).

Bien no se descarta bajo ninguna circunstancia que el multiculturalismo y la globalización son temas análogos y vinculados con lazos muy visibles. Pero el aumento desmesurado de las desigualdades económicas y sociales ha llevado al mundo ha conllevado a la emigración desde las zonas menos desarrolladas a zonas más avanzadas del planeta, existiendo un impacto y extendiéndose de personas con culturas diferentes, pero la globalización y su adorado modelo neoliberal ha supuesto el deterioro de muchos derechos sociales y el estado de bienestar, incrementando lógicamente las desigualdades en estos países avanzados en su interior (Abella, 2003: 135). El resultado de todo este proceso es la gran indiferencia de los habitantes que viven de forma cómoda y poseen una calidad de vida optima, y no carecen de nada; mientras que llegan buscando afanosamente nuevas alternativas para salir de la pobreza y con la esperanza de un retorno próximo a sus países de origen, esta situación ensombrece el panorama e insta a los gobiernos a buscar soluciones a tan grave problema. Decimos al unísono una frase que nos enseña a respetar los derechos humanos a los diferentes: Negar a los extranjeros la entrada en nuestra ciudad, y a nuestros ciudadanos el permiso para viajar por los demás países, es una cosa que no se puede hacer en absoluto, pues se calificaría de bárbara e inhumana por los demás hombres; nos echarían en cara que teníamos la horrible costumbre de excluir de nuestro país a los extranjeros y que nuestras costumbres eran rudas y salvajes” (Platón, 1999).

El artículo 26 de la Declaración Universal de los Derechos Humanos reza: “Toda persona tiene derecho a la educación... tendrá por objeto el pleno desarrollo de la personalidad humana y el fortalecimiento del respeto a los derechos humanos y a las libertades fundamentales, favorecerá la comprensión, la tolerancia y la amistad entre todas las naciones y todos los grupos étnicos o religiosos; y promoverá el desarrollo de las actividades de las Naciones Unidas para el mantenimiento de la paz" Sin duda alguna la UNESCO tiene una larga tradición en materia de educación de derechos humanos, de manera tal que ha venido afianzándose de forma universal, al reafirmar una visión humanista de la educación, afirmando que la educación no puede resolver por sí sola todos los grandes problemas surgidos por el denominado desarrollo, pero una visión holística, humanística de la educación puede conducir y contribuir a la adquisición de un nuevo modelo de desarrollo.

En ese modelo de manera apremiante debe estar vinculado la propuesta de un desarrollo sostenible, las discusiones para lograr una paz duradera en todo el planeta, la inclusión y la justicia social, y la suma de principios tan importantes dentro de un modelo económico excluyente como es el capitalismo. A este modelo se le debe sumar también la formación ética y axiológica, siendo que una verdadera visión humanística y holística del desarrollo debe afrontar y erradicar la violencia, la discriminación hacia las comunidades homosexuales, la intolerancia, las xenofobias y los odios hacia las demás creencias religiosas que existen en el mundo. En lo concerniente a la tarea educativa se cree que es por medio de esta tarea que es posible dejar a tras o erradicar las practicas utilitaristas, economicistas, consumistas de miradas cortas para integrar una mirada que mire las miradas y haga posible las dimensiones múltiples de la existencia humana. Esta holística nos embarca en una nave que permite el ingreso de: discapacitados, miembros de la comunidad LGTIBIT, minorías indígenas y afrodescendientes, y todo ser humano (UNESCO, 2015).

La ceguera propia de un modo de conocimiento, que, al desarrollar la compartimentación, fragmentación de los saberes, permite la desintegración de los grandes problemas fundamentales y globales que exigen un conocimiento interdisciplinar; el occidental-centrismo, que nos ubica en el sitial de la racionalidad nos entrega la ilusión de ostentar lo universal. Por lo tanto, no es solo nuestra ignorancia, también es nues-

Revista Política, Globalidad y Ciudadanía, Vol. 4 No. 8, Julio - Diciembre 2018, Universidad Autónoma de Nuevo León, Monterrey, México, ISSN 2395-8448. pp 20-36. http://revpoliticas.uanl.mx/index.php/RPGyC/article/view/100 
tro conocimiento lo que nos produce esa ceguera y la misma ignorancia (Morín, 2011). Retomando estas afirmaciones se mira las desventajas que traen el modelo de educación parcelario que divide y fomenta la separación de saberes. Eso en estos momentos genera esas cegueras e ilusiones. El conocimiento que proponemos es venido, del término humano es rico, contradictorio, ambivalente: de hecho, como dice Morín, es demasiado complejo para las mentes formadas en el culto de las ideas claras y distintas. El conocimiento que estamos proponiendo es complejo: porque reconoce que el sujeto humano que estudia esta también incluido, inmerso en su objeto. Este concibe inseparablemente unidad y diversidad humanas: el hombre es un ser bio-pisco-socio-cultural e histórico (Morín, 2001, p. 17).

Atendiendo a estas afirmaciones, son contundentes y acertadas las frases de algunos pensadores: "Una concepción compleja del análisis de lo social debe oponerse, por tanto, a la forma como se ha institucionalizado su conocimiento, que ha reconocido en cada disciplina una parcela estrecha de su objeto de estudio y aún ha fragmentado de manera interna cada ciencia, destruyendo así la multidimensional dad, el acercamiento multiparadigmático y sus múltiples interacciones" (Luengo, 2009, pp. 1-2).

La economía ha producido riquezas múltiples e inauditas y al mismo tiempo miserias en todos los ámbitos es precisamente la falta de control la que da rienda suelta a la riqueza de pocos contra la pobreza de muchos. Por eso se dice que la globalización es lo peor que le ha podido suceder a toda la humanidad. Estamos abocados a perder el tren de la historia. Esto debería enseñarnos que este mundo del siglo XXI será un mundo dominado por grandes asociaciones de países, que se integran cada vez más; este será un mundo de grandes transaccionales y de múltiples redes comunicacionales. Mucha razón tenía Octavio Paz cuando decía estas palabras para un mundo como el nuestro: "Gentes de las afueras, moradores de los suburbios de la historia, los latinoamericanos somos los comensales no invitados que se han colado por la puerta trasera de occidente, los intrusos que han llegado a la función de la modernidad cuando las luces están a punto de apagarse -llegamos tarde a todas partes, nacimos cuando ya era tarde en la historia, tampoco tenemos un pasado o, si lo tenemos, hemos escupido sobre sus restos, nuestros pueblos se echaron a dormir durante un siglo y mientras dormían los robaron y ahora andan en andrajos, no logramos conservar ni siquiera lo que los españoles dejaron al irse, nos hemos apuñalado entre nosotros..." (Paz, 1993 citado por Moena Gonzales, 1997, p.237).

El desarrollo del desarrollo produce y acentúa sus crisis y lleva de la mano a la humanidad a grandes desastres en cadena. Es en otras palabras más apropiada, lo que nos muestra el sociólogo Ulrich Beck. En este sentido nos plantea que vivimos el pasaje desde la modernidad industrial hacia una sociedad del riesgo, por medio de una metamorfosis producida por la confrontación de la modernidad con las consecuencias no deseadas de sus propias opciones. El concepto de riesgo implica invertir la relación entre pasado, presente y futuro. Entonces el futuro adopta su lugar como causa de la experiencia y la acción actual. Nos dirigimos hacia esa metamorfosis. Existe un peligro nuclear que se agrava cada vez más por las mismas cegueras del conocimiento, siendo que toda crisis implica la necesidad de superar la misma historia humana (Beck, s.f.)

Existe una clara apreciación que guarda relación con los juicios que se han adelantado en esta parte del trabajo; y son precisamente las palabras del Teólogo y filósofo francés: Teilhard de Chardin quien distingue en el universo un "fuera" y un dentro. Nos dice él que el error grande de las ciencias fue el considerar solamente el "fuera" como si todo se redujera a un simple mecanicismo, a una máquina, pero hay que asegurar la continuidad física en todas sus fases, a este vasto desarrollo ampliado a distintas miradas de elementos esparcidos en la inmensidad de los tiempos, un solo mecanismo sin ninguna duda es: la educación; y yo le agregaría a este juicio para este siglo XXI una educación integral.

Una educación que se continua y emerge bajo forma reflexiva al igual que en sus dimensiones sociales, el trabajo biológico hereditario que desde sus génesis hace emerger el mundo dirigiéndolo hacia zonas de conciencia cada vez más elevadas. En esta dirección sobre el presente son ricas las palabras de reflexión 
filosófico-teológicas de Teilhard que desde la educación se opera a la vez directa e indirectamente la incorporación del mundo al verbo encarnado para vivir y comprender lo humano. En el momento presente y sobre el planeta tierra es menester tener en cuenta las apreciaciones desarrolladas por Fontalvo, Peralta (2008) Página 15, al referirse especialmente al concepto de calidad de la educación, está afirmando este investigador que la formación humana va cogida de la mano en su relación con los sujetos y goza de manera inmanente del acompañamiento de los desafíos sociales y también culturales. Por lo tanto, la calidad de la educación y por ende la formación en Derechos humanos se extiende a las necesidades e intereses al igual que los retos de la condición Humana y toma de manera diferente el concepto de reforma, palabra modesta pero implícitamente con un sentido de importancia en el aprendizaje de los humanos, pues ella implica cambio en el pensamiento y reforma de la sociedad. El sentido de formación compleja entonces apunta hacia el futuro en una sociedad planetaria violenta e incomprensiva cada vez más.

Los usos y costumbres indígenas y el respeto a los derechos humanos

Tratar el tema de los usos y costumbres indígenas, lo mismo el respeto a los derechos humanos, no es cosa que se pueda apreciar de manera simplista. Hacerlo desde una sola mirada implica dejar por fuera muchos aspectos que son importantes para un estudio serio y concienzudo. Existe en ciertas comunidades indígenas una cosmovisión de orden particular que los identifica y los hace fuertes a pesar de la intromisión del blanco a sus tierras y la progresiva globalización avasallante del terrateniente que los despoja de sus tierras y pretende aniquilar su cultura. Caso particular que llama poderosamente la atención y que es significativo para una mayor comprensión de sus usos y costumbres, como también el respeto por los derechos humanos:

"Somos hijos de la tierra

Somos generaciones de vida

Somos pueblos en resistencia"

(Risaralda, 2012)

Desde el punto de vista histórico, existen muchas versiones que ventilan el problema y lo acomodan a unos intereses particulares, omitiendo muchas situaciones que descubren y enrostran el grave problema que viven nuestros indígenas en Colombia.

El verdadero propietario de la tierra en nuestra geografía nacional, son los indígenas. Ellos son víctimas del conflicto que durante muchos años ha conmovido al país, y los viene desplazando hacia las principales ciudades. En cuanto al respeto de los derechos humanos, se puede argumentar que dichos derechos solo privilegian un universalismo abstracto, que no tiene espacio para las comunidades indígenas y que poseen un lenguaje distinto. La idea sería tenerlos a todos en cuenta e insertar las políticas multiculturalitas dentro de las estrategias de esos derechos humanos que tenga la posibilidad también de gozar del derecho a la distintivita, el derecho a lo propio, derecho a lo preferente y a su mejoramiento, económico y social. (UNICEF, s.f.).

La globalización a la que asistimos, nos conduce a mirar nuevas formas de comprensión y articulación que permita la humanización de lo humano. Siendo que el lenguaje legitimo para hacer visible el problema que afronta muchas comunidades indígenas en el planeta, como el despojo de sus tierras, el marginamiento y desplazamiento y el desconocimiento de su cultura, sea la praxis de una democracia y la posibilidad de crear muchos derechos humanos multiculturales en un contexto de la diversidad y legalizar las luchas indígenas sin politizar, ni mucho menos darle el carácter de terrorismo (FIDH, 2004). Es por medio de un diálogo intercultural que es posible establecer la capacidad para proteger y al mismo tiempo impulsar el respeto a los derechos humanos, tal cual como se encuentra escrito en el Convenio Europeo de derechos humanos, son entonces la democracia y el Estado de derecho, con el fin de promover el entendimiento mutuo. Aquí también existe la direccionalidad de brindar protección y la puesta en práctica la diversidad cultural 
y la concepción de la dignidad humana; y le agregamos también la enseñanza de la condición humana y la comunicación. Estos puntos consagrados la mayoría en este libro, hace posible dirigir y reconocer las diferencias existentes conforme a los valores universales. Explica también este libro, que, para seguir catapultando este propósito del diálogo intercultural, es camisa de fuerza ajustar y afianzar diversos aspectos relacionados a la gestión democrática de esa diversidad. Afirma de forma coherente el consejo de Europa que está completamente convencida de que todos tenemos la responsabilidad moral y común de crear una sociedad en la que todos quepamos, vivamos con los mismos derechos, y obviamente los mismos deberes. Aquí también es requerirle incluir a los pueblos indígenas y a las negritudes en todo el mundo. Esto debe regir para todos. (Consejo de Europa, 2008).

En Colombia todos estamos marcados por la violencia en distintas facetas. La violencia está presente en todos los ámbitos. Desde la llegada de los invasores españoles quienes impusieron la esclavitud por medio de las instituciones socioeconómica dictadas desde la metrópolis europea. A propósito de la violencia y sus orígenes históricos, resulta importante recordar, que fue el oro la presa que más codiciaba el Blanco Español. Fue la base para exterminar la mano de obra indígena. Para la muestra un botón: "en efecto Fray Antonio de Montesinos, en la tosca iglesia improvisada y techada de paja, en vísperas de Navidad del año 1.511, se inició una cruzada que haría historia, Fray Antonio de Montesinos en el pulpito y frente a todos los grandes de la isla pronunció el famoso sermón que transformaría los destinos del mundo nuevo:

... me he subido aquí -les dijo-yo soy la voz de Cristo en el desierto de esta isla, y por tanto conviene que, con atención, no cualquiera, sino con todo vuestro corazón, la oigáis; la cual voz o será la más nueva que nunca oísteis, la más áspera y dura, la más espantable que jamás pensasteis oír...Todos estáis en pecado mortal y en él vivís y morís, por la crueldad y tiranía que usáis con estas inocentes gentes. Decid. ¿Con qué derecho y con qué justicia tenéis en tan cruel y horrible servidumbre a questos indios?" (Liévano, 1987).

La historia es una ciencia que nos permite ventilar los acontecimientos históricos de una manera dialéctica. Precisamente es ella la ciencia más apropiada para conocer en detalle, la barbarie en que un pueblo como el indígena de América Latina, fue sometido, empleando la cruz y la espada. A este sometimiento hay que anexarle las denominadas instituciones socio-económicas, que sirvieron como forma de esclavitud y exterminio casi en su totalidad de la mano de obra indígena; pero la colonia permitió la creación de impuestos para ser pagados al erario español por parte de los criollos.

Hoy pagamos un precio muy alto, porque después de todo las violaciones e imposiciones, aún continúan por una clase dirigente genuflexión del imperio americano. La llegada del colono blanco nos marcó y nos sigue sometiendo a su capricho, con políticas, y guerras genocidas. El narcotráfico y el empleo de la mano de obra indígena para sembrar y recoger los denominados cultivos ilícitos ha sido la desgracia. No ha existido en nuestro país una verdadera reforma agraria que favorezca a los campesinos e indígenas que son los verdaderos dueños y tienen en su poder los títulos de propiedad que nos muestra la misma historia. Ese ha sido el camino nuevo emprendido por los indígenas y hombre pobres del campo; después de la revolución cubana en el año 1959 se inició en Colombia la denominada violencia, un conflicto entre liberales pobres y conservadores pobres. Se alzan voces que afirman de manera consistente (Ospina, 2007): que cuando una sociedad no es capaz de realizar a tiempo las reformas requeridas y que el orden social reinante exige para su continuidad la historia las resuelve por sí misma y a su manera con costos elevadísimos para todos. Siendo que el Frente nacional organizado por los azuzadores liberales y conservadores frenaron las posibilidades de un desarrollo constitucional, moral y político que acrecentó el poder de estas elites burguesas. (Ospina, 2016). Pero este no es el final de este cuento.

Surgen entonces los primeros brotes de inconformismo liderado por los liberales. La aparición de una 
guerrilla Liberal con influencias político-ideológica de la Habana Cuba, quienes lideraron un proceso emancipa torio del imperialismo norteamericano, con el derrocamiento de Fulgencio Batista en el año de 1959.Las guerrillas en sus inicios estaban influenciadas por la filosofía y modelos de la URSS. Pero todo tiene su final. La perestroika, permitió el derrumba del bloque socialista que se mantuvo aproximadamente hasta la década de los ochentas. Entonces entro a jugar un papel muy importante el narcotráfico, una patología social que, para Colombia, ha producido los actos de violencias más salvajes e inhumanos, y con un acompañante; el paramilitarismo. Güerilla, Paramilitarismo y Estado, forman una trilogía digna de analizar y de estudiar con mucho detenimiento para poder entender un conflicto que comenzó hace ya mucho tiempo, es la historia la que puede brindarnos la información real de estos sucesos y la responsabilidad que le compete a cada uno de estos organismos. Pero se hace la salvedad que esta responsabilidad es más que todo del gobierno de turno.

El resultado de estos sucesos; es un sin número de desparecidos, desplazados, asesinatos y el genocidio más brutal de la historia colombiana. En este escenario, reina la injusticia, la impunidad, la corrupción, elementos que son necesarios para descubrir el gigante problema de una nación como la nuestra. Según Amnistía Internacional, en el conflicto armado interno que vive nuestra nación, hasta el 1 de diciembre del año 2016, la Unidad de víctimas, establecida por el gobierno, ha registrado casi 8 millones de víctimas del conflicto que data desde el año de 1985, entre los que había unas 268 mil víctimas de homicidios, la mayoría civiles, más de 7 millones de víctimas de desplazamiento forzado; alrededor de 46 mil víctimas de desaparición forzada; al menos 30 mil casos de tomas de rehenes; más de 10 mil víctimas de torturas; y aproximadamente más de 10.800 víctimas de minas terrestres denominadas, también quiebra patas).

Las luchas del indio que bajo de la montaña al valle de la civilización

La base de la cultura de un pueblo es sin duda su práctica, su experiencia cotidiana y su proyección histórica, su modo de vida, su legado social que le va dando forma a su forma de pensar, de expresarse, de entender su mundo propio y el mundo de los demás, incluyendo su todo espiritual mental conformado por elementos interdependientes, en un fondo colectivo de saberes, creencias, mitos, valores y fines, conglomerados de actitudes y su ideología sui generis, o propias de sí mismas. Este recorrido de orden cultura nos permite ver muy de cerca la situación del indígena en Colombia. Toda la desgracia comenzó con la incursión del blanco europeo, pero luego vinieron otros episodios desgarradores con la llegada de latifundistas que se apropiaron de las tierras, usurparon sus propiedades y desbarataron poco a poco sus creencias, hoy son los que han llegado tarde a la modernidad (Vasco, s.f.).

La cultura está asociada al mundo de la construcción e invención a la gran creatividad. En un mundo predador como el nuestro, donde la educación se dedica a llenar la cabeza de todos, o sea una cabeza repleta y no una cabeza bien puesta. Si entendiéramos estos aspectos los recursos de los pobres negros y campesinos pobres no serían jamás esquilmados. A este problema hay que agregarle otro pedazo que siempre se deja por fuera de todo programa gubernamental. Es el componente denominado el narcotráfico. Es por esto y mucho más que al indio se la ha perseguido en todos sus intereses morales materiales y también espirituales por la llamada civilización y esta se los ha arrebatado. El indio se debate entre la vida y la muerte de sus tradiciones:

Mis intenciones son de todo corazón proteger el futuro de mi raza que duerme todavía en la ignorancia, para hacerle frente al enemigo de nosotros los indígenas, y que conozcamos la pradera de nuestros grandes destinos, y no corramos como mujeres enamoradas abandonando el cariño de sus padres, a buscar la gran sociedad del estado de la civilización, porque nosotros los indios tenemos más memoria, y se nos presente la inspiración más ligera que el relámpago. El indio se pasea mejor y más rápido que la abeja en todas las flores del jardín de las ciencias” (Quintín, 1973). 
Pese a que existen muchos propósitos para proteger a los indígenas, afrodescendientes y campesinos en el territorio nacional...Esa idea es más que toda una ilusión, una utopía y proyecto solo imaginario en la mente de los gobernantes de turno. En un país de alta violencia como Colombia, es urgente enfrentar el asunto de las violencias, porque son múltiples las formas de expresión y materialización de esos actos violentantes, por medio de una formula apropiada que integre a toda la sociedad en general. Sabido es que en nuestro país se han elaborado distintas reformas parciales en cuanto a la educación, aunque aparentemente se tiene en "cuenta" las comunidades indígenas habitantes de nuestro territorio, incluso se predica y se visibiliza el tema de sus derechos, pero solo es pura letra muerta. Estos grupos indígenas, los afrodescendientes, los pobres son excluidos, incluso vistos por la sociedad de ricos y pobres como objetos. El trato que reciben estos es de carácter degradante y xenofóbica. Se cree que es por medio de la educación que se puede realizar un trabajo o una especie de reforma al pensamiento que logre hacer transformar las mentalidades humanas, e inculcar en los niños el respeto a las diferencias o en otros aspectos en un lenguaje menos coloquial las denominadas alteridades.

La educación es un proceso de formación permanente. Eso significa que es inacabada, es un constructor de orden epistemológico y axiológico, supeditada a los grandes cambios impuestos por la tecnología de este siglo XXI. El educador de hoy debe estar untado de estos cambios y presente a los cambios emitidos desde la denominada postmodernidad. Postmodernidad que nos induce a ver y asumir el mundo de manera no lineal y ortodoxa. Para nadie es un secreto que la postmodernidad es el producto de la derrota del proyecto de la modernidad emitida durante la ilustración y la caída de los grandes conceptos filosóficos y políticos que no lograron sus fines como se anunció en esos siglos por los pensadores de ese momento histórico.

En este proceso, si es posible de usar el término de carácter Marxista muy popular en la década de los sesentas: dialéctico. Que significa cambio, transformación y quizás mejoría para algunos legos de la política, la sociología y la historia. Se emplea una afirmación que describe y es la punta de lanza del tema de la educación intercultural y la democracia en sus pros y contras; como la siguiente: "En algunos países de la región Andina se desarrollaron profundas reformas estatales en las décadas pasadas a través de asambleas constituyentes, que produjeron resultados óptimos para el tenido institucional de la democracia. Eso puede significar unos avances en materia democrática, social, educativa, que ajuicio personal es un avance en medio de esta vorágine de violencia generalizada y auspiciada por los medios de comunicación más sofisticados máxime si en los años noventa se logró incorporar instituciones de democracia participativa en sus constituciones políticas o carta magna y se reconoce el carácter multicultural y pluriétnico de sus sociedades y puso en la palestra el debate plurinacional de la sociedad con el reconocimiento de los derechos colectivos indígenas y la praxis de reconocimiento entre democracia, diversidad social e interculturalidad(Nicolás Trotta y Pablo Gentili,2016).

Todos estos avances son importantes, si se tienen en cuenta que todo podría ser letra muerta sino se difunde a las nuevas generaciones y se les inculca la existencia de estas formas de democracia. Es por medio de una educación en derechos humanos, como eje transversal que sería posible realizar ese sueño de una sociedad más justa y solidaria, respetuosa de las diferencias y portadora de un sistema que abarque las múltiples diferencias surgidas en esta postmodernidad. Este proceso debería tener como acompañante inigualable las propuestas venidas desde los saberes de la educación para el futuro. Freire plantea: que la educación, es entonces, un campo de prácticas y valoración social y culturalmente asumidas por lo que se valora al sujeto.

El proceso de enseñanza aprendizaje es un proceso dialógico que permite la otredad y la nostridad, es un proceso comunicativo cargado de sentimientos y relaciones humanas, capaces de transformar al hombre y no es una tabula rasa como se dijo en Existe en el ser humanos un ethos. De aquí se desprende los procesos de la ética del que la pléyade de pensadores nos ha persuadido desde hace muchos siglos atrás desde los más materialistas como Nietzsche hasta los más idealistas como Santo Tomás de Aquino. Al margen de 
esta discusión el hombre es un proyecto que merece ser educado. La educación en derechos humanos es la alternativa de eso que no quepa la menor duda. Este proceso no es un conjunto de leyes y decretos escritos en manuales de derechos, sino que deben estar acompañados de procesos vivenciales que acompañen a los padres de familia, comunidades indígenas, afrodescendientes en un todo la vida y el respeto de esta. Hay un concepto propio de esa predicación de la enseñanza de los derechos humanos: La dignidad es un valor que se debe mostrar en los diferentes actos de la sociedad; es desde la cuna que debe ser predicado a través de actos y asumido como un valor humano en todas las etapas de la vida.

En torno al concepto de dignidad humana y su proceso de aplicabilidad al campo pedagógico y la enseñanza de los derechos humanos se encuentra presente y se suma a una percepción digna de tener en cuenta en todo proceso de aprendizaje que dé cuenta de los derechos. Hay un término propio de la categoría de los derechos humanos: la dignidad. Esta goza de diferentes significaciones y repercusiones, está presente en las constituciones españolas desde 1812. Siendo que el término se aplicaba como factor de distinciones, o de prestigio que hacían diferenciar unas personas de otras, pero hay que establecer las diferencias que no son por su patrimonio material, sino por su patrimonio moral. Suponemos que, con el logro de los derechos del hombre y el ciudadano, quedó establecido no solo la dignidad humana, sino la misma condición humana. (Chueca, 2015).

Existe muchas fórmulas para afrontar los graves problemas de violación de los derechos humanos en el planeta; lógicamente que la más ajustada a nuestros tiempos y creo que a los tiempos pasados, fue y seguirá siendo la educación. Se ha venido haciendo un recorrido desde los griegos hasta nuestros días actuales del siglo XXI y no cabe la menor duda que es la educación la vía más segura para transformar la sociedad; acogemos significativamente el concepto de vivir en nuestra convulsionada sociedad: Vivir es una aventura. El error y la ilusión dependen de la naturaleza misma de nuestro conocimiento. Eso desde la perspectiva de los derechos humanos, quiere significar, que el error y la ilusión van a depender de nuestro conocimiento y vivir es afrontar sin cesar el riesgo de los errores.

El problema no se puede analizar desde una mirada simple, sino desde miradas complejas, siendo que la fórmula que lo visualiza es la propuesta del pensamiento complejo. Todo lo que se enseña en las aulas de clases en todas las etapas constituye en cierto modo, una ayuda para vivir. Es necesaria el aporte brindado por las ciencias humanísticas y las científicas. Pero lo más esencial seria unirlas y de esa manera construir una cultura permanente y auxiliar de nuestras vidas donde quepamos todos, sin discriminación de ninguna especie. (Morin, Edgar) Enseñar a vivir: manifiesto para cambiar la educación-1 Edición ciudad Autónoma, Buenos Aires: Nueva Visión, 2015).

El papel de la mujer en la cosmovisión indígena

Los problemas de violencia contra la mujer, es un fenómeno que también afecta terriblemente a la mujer indígena en toda la América Latina., atacando de forma directa el principio básico del derecho a la vida. Derecho que siempre ha sido vulnerado y desconocido por muchos gobiernos y dictadores de todo el multiverso. Según el documento de la CSW57, marzo del 2013 y gracias a la agencia española de Cooperación Internacional para el Desarrollo- AECID y la Fundación Ford, quienes por medio de este documento Violencia y Mujeres Indígenas, han facilitado una información adecuada y transparente para conocer y visibilizar más de cerca este asunto que poco alcance ha tenido en el contexto de la sociedad del siglo XXI.

Es poco lo que se ha dado a conocer por las instituciones gubernamentales sobre la violencia contra la mujer indígena. Llama poderosamente la atención para todos aquellos que tenemos la oportunidad de abordar de una manera más visible los problemas que padecen las mujeres en ciertas comunidades indígenas. Tan olvidados están que estos problemas pasan inadvertidos para los ministerios de cultura y otros ministerios; el problema es bastante complicado, tan complicado que a veces nadie quiere comprometerse 
a denunciar el despojo de sus tierras sagradas y tesoros invaluables para sus creencias religiosas y ancestrales. Para los Blancos, estos aspectos son de poca valía; a estos blancos solo les interesa son sus tierras, y el despojo que de estas tierras extensas se haga.

Pero el problema no termina allí. La agencia española de Cooperación Internacional AECID, informa en sentido estrecho de salvaguardar la vida y brindar posibilidades de desarrollo que hagan más saludable, activa y propositiva la vida de la mujer indígena. Las mujeres en todo momento de la historia de estos pueblos han encabezado la lucha por el territorio ya que la mujer indígena es la propulsora sobre la biodiversidad, de tal manera que todo tipo de violencia contra la mujer indígena afecta una u otra forma la existencia de los pueblos indígenas y la destrucción de una riqueza tradicional y la diversidad de la sociedad en su todo.

Es digno de resaltar y tomar como derrotero el informe efectuado por esta agencia CSW57 con la misma fecha y la fundación Ford; quienes afirman que los países que reúnen el mayor número de indígenas (87\%) lo constituyen México, Bolivia, Guatemala, Perú y Colombia y más de la mitad de sus integrantes lo conforman las mujeres. Pero lo más asombroso de todo este proceso es la exclusión de la mujer, siendo el racismo y la discriminación y las xenofobias constituyentes de una política provenientes de Estados y gobiernos propulsores de exclusión y abandono de estas comunidades ricas en cultura y de una espiritualidad incomparable. Entonces la invisibilzación de todos sus derechos hace imposible o mejor dicho limitan el acceso a los sistemas jurídicos y a la participación justa de los derechos, tales como acceso a la salud, educación, salud, participación política. Existen parámetros dictados por las organizaciones internacionales que promulgan acuerdos y tratados que garantizan y demandan sus derechos Colectivos e individuales, de igual manera el reconocimiento de sus territorios soberanos-llámese resguardos para el caso de Colombia o reconocimiento jurídico de su hábitat natural.

La propiedad en el mundo indígena

La tierra es la vida del indígena. "La Tierra resume los diferentes aspectos simbólicos que son la base no solo de la riqueza y el poder, sino también de la cultura" (Nobre y Brito, 2017. P.8). Los verdaderos propietarios de las tierras en América son los indígenas. "La Tierra resume los diferentes aspectos simbólicos que son la base no solo de la riqueza y el poder, sino también de la cultura" (Nobre y Brito, 2017. P.8). Esto puede ser analizado tomando como punto de partida la carta del gran jefe Sehtal. Este significa históricamente la relación existente entre la tierra y el espíritu indígena. No solo en Colombia nuestra tierra, sino también en ese mundo denominado global. Por eso es significativo tomar este mensaje cuando el presidente de los Estados Unidos, Franklin Pierce en el año 1854 le dirige una carta al Gran Jefe Seattle de la tribu SUWAMISCH para que le vendiera los territorios del noroeste de los EE.UU.

Es muy importante conocer la respuesta entregada por el gran jefe Seattle, donde afirma que cada pedazo de la tierra es sagrado, los ríos son nuestros hermanos y calman la sed de cada criatura viviente. Pero sigue el exterminio propiciado por el hombre blanco que se cree dueño de todo; el exterminio de los animales, la desaparición de la fauna, miles de pájaros y mariposas que hacen parte del paisaje bello que constituye el gran concepto de poder de los indígenas en sus tierras. La tierra lo es todo para el indígena en todas las partes del mundo, desde el polo norte hasta la Patagonia.

Sin embargo, el mundo occidental ha establecido una política hegemónica en lo político, en lo económico, pero imponiendo una visión única de ver al mundo. Las privatizaciones de las tierras están a la orden del día. En Colombia por ejemplo los grupos paramilitares despojaron a sangre y fuego grandes extensiones de tierra. Tierras que como se ha dicho son sagradas. La explotación de dichas tierras sigue en manos de grandes empresas internacionales que usufructúan los bienes de esos territorios. El campesino y el indígena han sido víctimas de la violencia acaecida en Colombia durante muchos años de guerras entre el Estado y los grupos insurgentes. Son miles de indígenas que han venido a las grandes metrópolis, junto con sus 
pocas cosas y han engrosado las filas de la miseria y sentándose en barrios tuguriales y Presa de la violencia urbana, que también ha desencadenado problemas sociales y enfermedades que diezman dicha población y lo doblegan al sufrimiento y al desprecio. (La torre Restrepo, 1/03/14 11:23) nos ilustra sobre este punto, afirmando: "frente a este disputa de intereses, los Estados dueños del monopolio de producción del Derecho se han desplazado en una dirección más garantista de los derechos de los pueblo indígenas" Ello significa que con esto se busca responder al conjunto de demandas y protestas de esos grupos étnicos Existen algunos instrumentos de orden legal e internacional que reconocen los derechos de los pueblos indígenas y lo reafirman en sus proclamas, como la Declaración de la Naciones Unidas sobre los derechos de todos los pueblos indígenas del año 2007 y acogida y ratificada por 143 países del mundo. Por aquí está la cosa en materia de propiedad indígena. Pero a pesar de todas estas ratificaciones, siguen en Colombia las explotaciones y desplazamientos de indígenas de sus propios territorios; caso especial los indios Cogui en la sierra Nevada de santa marta, que es su lugar de origen, y el santuario donde viven con su familia. Este es su mundo.

"Los pueblos indígenas y las comunidades afrocolombianas comparten una vulnerabilidad en especial con los conflictos de tierras" (Alfonso, Grueso y otros. P.202) Estas comunidades también comparten algunos mecanismos de protección legal, tales como el derecho a su identidad cultural y el derecho a la consulta previa. Ese derecho a la consulta previa es desarrollado por el convenio 169 de la Organización Internacional del Trabajo Declaración Universal de los pueblos Indígenas de la Asamblea General de las Naciones Unidas, de igual manera el conjunto de criterios adjuntos a la Corte Interamericana de los Derechos Humanos y la Corte Constitucional Colombiana. La consulta previa: Para (Rodríguez Morris y otros, 2010) según el programa de justicia Global y Derechos Humanos de la Universidad de los Andes en Colombia, especificando en la consulta previa a Pueblos Indígenas toma al (CDR) tras la entrada en vigor del Convenio Internacional sobre la eliminación de todas las formas de discriminación contra estos pueblos de minorías étnicas a partir del año 1969.

Este ente como lo es el (CDR) tiene como objetivo recomendar medida especificas a los estados pertenecientes y firmantes de dichos convenios, sobre todo en situaciones donde se desarrollen actos discriminatorios contra estas minorías étnicas, de igual manera tiene la funcionalidad de recibir quejas en casos específicos donde se discrimine y se atente culturalmente contra sus costumbres y creencias de todo ámbito. (Rodríguez, 2014) Afirma: Teniendo en cuenta la importancia jurídica que posee un instrumento como este el de la consulta previa, que se constituye en un instrumento jurídico que hace reconocimiento de los derechos políticos, culturales, territoriales y sociales de las comunidades étnicas sentadas en el territorio nacional, siendo que este es el teatro de los acontecimientos que les permite el logro de su verdadero desarrollo atado a sus costumbres ancestrales y tribales. Todas estas costumbres deben respetarse y vincularse directamente con algunos de estos aspectos:

La consulta previa: Se relaciona con cualquier medida legislativa que lesiones los intereses de estas comunidades. Participar siempre que sea posible en los beneficios que reporten ciertas actividades, explotación de recursos mineros y demás; Enseñarles a sus niños a escribir y leer respetando su propia lengua, es necesario consultarse de manera imperiosa los planes de desarrollo a esas comunidades y de manera transparente con un lenguaje claro, de respeto, culturalmente adecuada, de buena fe y lograr el consentimiento. En fin, una concertación dialógica que integre también el consentimiento libre, previo e informado, basado en el respeto a la libertad y a la libre determinación de todos los pueblos herederos de las culturas.

Criterio etnolinguistico y derechos diferenciados de autogobierno

En cuanto a este aspecto, vale la pena anunciar lo interesante que es tomar al pie de la letra este punto sin omitir cualquier detalle. El criterio etnolingüístico, resulta muy interesante desde el punto de vista histórico. Histórico, porque nos revela la gran riqueza de lenguas y dialectos ricos que conllevan a babelizar el rico mosaico de formas de comunicación entre estas comunidades, dignas de tener en cuenta en un estudio

Revista Política, Globalidad y Ciudadanía, Vol. 4 No. 8, Julio - Diciembre 2018, Universidad Autónoma de Nuevo León, Monterrey, México, ISSN 2395-8448. pp 20-36. http://revpoliticas.uanl.mx/index.php/RPGyC/article/view/100 
que se relaciona con los derechos humanos. Se trata pues de dilucidar ese rico mosaico y asociarlos a los derechos diferenciados. A propósito, diferenciados. ¿Por qué diferenciados? Existe entonces el derecho a exigir derechos nuevos derechos positivos y legales y es una necesidad que poseen las minorías étnicas de reconocimiento de sus capacidades deliberativas. Kymlicka atiende en ese sentido la pertinencia cultural a un mismo Estado a una etnia, aunque este no hace claridad sobre la pertinencia a un grupo oprimido.

En este sentido se piensa la interculturalidad. Hay una visión ofrecida desde la invitación ofrecida a entender el derecho diferenciado desde (Abya-Yala/América Latina Edwin Cruz Rodríguez, 2013) Para Kymlicka,1969 más allá de la tolerancia y la coexistencia: respeto y convivencia el multiculturalismo tiene la gran pretensión de conciliar los valores de la filosofía liberal-tolerancia, libertad individual, igualdadcon los derechos diferenciados con el empleo del grupo requisito para salvaguardar la igualdad, justicia y quizás la libertad entre las culturas múltiples. Eso quiere significar o darnos a entender que los derechos del autogobierno son concernientes a una autonomía política, a la territorialidad jurisdiccional que vuelvan permisiva la autodeterminación de esos pueblos al igual que su desarrollo propio y de acuerdo a sus ideas y pensamientos culturales y políticos.

\section{3.- MÉTODO}

Diseño

El enfoque investigativo de la presente investigación es cualitativo, de acuerdo con Hernández, Batista y Fernández (2014) “Utiliza la recolección y análisis de los datos para afinar las preguntas de investigación o revelar nuevas interrogantes en el proceso de interpretación" (p.7).

Alcanzando un diseño no experimental "Que se realiza sin la manipulación deliberada de variables y en los que sólo se observan los fenómenos en su ambiente natural para después analizarlos" (Hernández, Batista y Fernández, 2014, p. 149). El alcance establecido es el exploratorio "emplean cuando el objetivo consiste en examinar un tema poco estudiado o novedoso" (Hernández, Batista y Fernández, 2014, p. 91).

Instrumentos

Para la construcción del marco teórico-conceptual de la teoría del modelo inclusivo de educación desde el pensamiento complejo, se consultaron un total de veintiún referencias bibliográficas utilizándose como instrumento las ideas, argumentos y proyectos que fueron interpretados desde una perspectiva analítica y crítica.

\section{Procedimiento}

Con relación a la comprensión del problema de la investigación se recopilan fuentes secundarias de documentos académicos. En el marco de referencia se definen los conceptos básicos relativos al modelo inclusivo de educación desde el pensamiento complejo. Una vez recopilada y analizada la información se construye el documento objeto de este trabajo. Por último, se realizan las recomendaciones y conclusiones conforme a los objetivos trazados (Oliveros et al, 2018, p. 72).

\section{4.- CONCLUSIONES}

De este artículo se desprende un sin número de apreciaciones muy importantes en el ámbito educativo y en especial en la educación para los derechos humanos en el contexto de la educación a todos los niveles existentes. Aquí se ha acudido una revisión exhaustiva sobre las falencias de algunas propuestas venidas de gobiernos y políticos de turnos que carecen de sentido y no conducen a una verdadera cultura de paz, ni se respeta, ni valora la diversidad cultural, ni se han mostrado verdaderos avances que sean bienvenidos y tomados en cuenta por el actual modelo de aprendizaje que nos rige; a nuestra consideración se viene otras debilidades que son también significativas, tales como la imposibilidad de enseñar el conjunto de saberes sobre derechos humanos con la mirada fija hacia las competencias y el conglomerado de leyes, tanto nacio-

Revista Política, Globalidad y Ciudadanía, Vol. 4 No. 8, Julio - Diciembre 2018, Universidad Autónoma de Nuevo León, Monterrey, México, ISSN 2395-8448. pp 20-36. http://revpoliticas.uanl.mx/index.php/RPGyC/article/view/100 
nales como internacionales, ya que estas deben estar también acompañadas de manera inmanente hacia una apertura a la otredad, si de respetar a los demás se trata. Pero se sigue cometiendo las mismas falencias de otrora. Por eso la vía que proponemos es la pedagogía compleja como exploración de una nueva esperanza para la humanidad, desenado que todos los educadores del planeta sean los protagonistas de esta reforma al pensamiento; siendo que la ética del género humano debe considerarse como afirma Morín como el bucle: individuo-sociedad-especie (UNESCO, 1999).

\section{REFERENCIAS}

Abella Vázquez, C. (2003). Globalización y multiculturalismo Universidad A de Coruña vol. VII, nm. 135. Recuperado de: http://www.ub.es/geocrit/sn/sn-135.htm

Bauman, Z. (2005). Vida Líquida. Editorial, Paidós y sociedad, p. 143.

Beck, (s.f.). La sociedad del riesgo: Hacia una nueva modernidad. Editorial siglo XXI

Cruz Rodríguez, E. (s.f.). Pensar la interculturalidad: una invitación desde. Quito

Fontalvo Peralta, R. (2008). Educar en la Complejidad. Barranquilla (Colombia); Ediciones Universidad Simón Bolívar, p. 15.

Freire, P. (1998). Educación y Transformación Social: Homenaje a Paulo Freire. España; Editorial Laboratorio Educativo, Caritas Española.

Donoso, G. (2015). La deserción escolar en América Latina.

Hernández, R., Fernández, C., y Baptista, P. (2014). Metodología de la investigación. México: Mc Graw Hill.

Kymlicka (1996) Ciudadanía multicultural una teoría liberal de los derechos de las minorías. México; Editorial Paidós-Ibérica.

Latorre Restrepo, S. (2014). Propiedad de la tierra y de los pueblos Indígenas, Blog. Barranquilla, (Colombia); Universidad del Norte.

Liévano Aguirre, I. (1987). Los grandes conflictos, económicos, sociales de nuestra historia. Editorial Tercer Mundo tomo (I).

Morín, E. (2001). El método: La humanidad de la humanidad-La identidad humana. Madrid; Editorial Cátedra, Grupo Anaya, S. A

Morín (2006). Modelo Educativo: Una aproximación axiológica de transdisciplina y pensamiento complejo. Hermosillo (México); MultiversidadMundoReal. Recuperado de http://www.multiversidadreal.edu. mx/wp-content/uploads/2012/10/modelo-educativo.pdf.

Morín y Delgado (2016). Reinventar la educación. Abrir caminos a la metamorfosis. 1era edición. México; Editorial Mundo real.

Morín, E. (2015). Enseñar a vivir: manifiesto para cambiar la educación-1 Edición ciudad Autónoma. Buenos Aires: Nueva Visión.

Moya, (2009). Informe sobre Desarrollo Humano para América Central 2009-UNDP

Nobre, M. y Brito, K. (2017). Atlas de las mujeres rurales de América Latina y el Caribe "al tiempo de la vida y los hechos". FAO, p. 8.

Trotta, N. y Gentili, P. (2016). América Latina: Democracia en la encrucijada (CLACSO) Editorial octubre 2016.

Revista Política, Globalidad y Ciudadanía, Vol. 4 No. 8, Julio - Diciembre 2018, Universidad Autónoma de Nuevo León, Monterrey, México, ISSN 2395-8448. pp 20-36. http://revpoliticas.uanl.mx/index.php/RPGyC/article/view/100 
Oliveros, O.; Waked, D.; Peña, C. y Lechuga, J. (2017). Diagnóstico Sobre la Planeación del Mercadeo en las Pymes de Boyacá. Revista Desarrollo Gerencial, 9 (2), 68- 87.

Sierra, A. y Grueso Castell Blanco, T. (2001). Derechos enterrados: comunidades étnicas y campesinas en Colombia, nueve casos de estudio. Bogotá; Universidad de los Andes - USAID, Editorial 1 KIMPRES Ltda., p. 202.

Zafra, L. (1917). Currículo y evaluación, críticos: pedagogía para la autonomía. Bogotá; Editorial iupUniversidad Nacional. 